\title{
Berberine: metabolic and cardiovascular effects in preclinical and clinical trials
}

\author{
This article was published in the following Dove Press journal: \\ Nutrition and Dietary Supplements \\ 10 September 2009 \\ Number of times this article has been viewed
}

\author{
Arrigo FG Cicero' \\ Sibel Ertek ${ }^{2}$ \\ 'Internal Medicine, Aging and \\ Kidney Diseases Department, \\ Sant'Orsola-Malpighi Hospital, \\ University of Bologna, Bologna, Italy; \\ ${ }^{2}$ Ufuk University, Medical Faculty, \\ Dr Ridvan Ege Hospital, Department \\ of Endocrinology and Metabolic \\ Diseases, Ankara, Turkey
}

\begin{abstract}
Berberine is a plant alkaloid with numerous biological activities. A large body of preclinical in vitro and in vivo studies support different pharmacological actions of berberine that could be potentially useful in the management of metabolic diseases associated with high cardiovascular disease risk, such as mixed hyperlipidemia, insulin resistance, metabolic syndrome, and type 2 diabetes. Moreover, it seems that berberine also exerts anti-inflammatory and antiproliferative effects that could play a role in the development of atherosclerosis and its clinical consequences. Recently, the metabolic effects of berberine have been demonstrated in humans, opening new perspectives for the use of this molecule in patient therapy. Larger and longer clinical studies need to be carried out to implement the definition of the therapeutic role of berberine in humans.
\end{abstract}

Keywords: berberine, cardiovascular disease, diabetes, cholesterol

\section{Introduction}

Atherosclerosis is by far the single most important pathological process in the development of cardiovascular diseases (CVD), which are the single most common cause of morbidity and mortality in developed countries. ${ }^{1}$ Moreover, while the relative rate of CVD in developing nations is lower than that of developed ("westernized") nations, the absolute number of people with CVD in developing nations now exceeds that in the West because $75 \%$ of the world's population live in developing nations. ${ }^{2}$

The main risk factors of CVD are known and educating the population about these risk factors is associated with a significant reduction of CVD risk. This is particularly evident when hypercholesterolemia is treated: a $1 \mathrm{mmol} / 1$ decrease in low-density lipoprotein-cholesterol (LDL-C) is associated with a $20 \%$ risk reduction of CVD events. $^{3}$ On the other hand, a large amount of residual CVD risk remains, even in patients adequately treated with the available antihypercholesterolemic drugs, mainly because of their limited action on lipid fractions other than LDL-C and on subclinical risk factors such as insulin resistance and overweight. ${ }^{4}$ Moreover, despite the best available treatments, a large number of patients at high risk for CVD events do not reach lipid targets suggested by the most widely accepted international guidelines for CVD prevention. ${ }^{5}$ Therefore, some patients refuse to continue the standard treatment because of intolerance ${ }^{6}$ or search for alternative treatments because of the fear of statin-related side effects. ${ }^{7}$

In this context, the aim of our review is to evaluate the metabolic properties of the natural alkaloid, berberine, and its potential application to CVD prevention.
Correspondence: Arrigo FG Cicero Clinical Pharmacologist, Lipidologist, "GC Descovich" Atherosclerosis and Metabolic Diseases Research Center Internal Medicine, Aging and Kidney Diseases Dept., Sant'Orsola-Malpighi Hospital, University of Bologna, Via Massarenti, 9, 40I 38 Bologna, Italy $\mathrm{Tel}+393498558017$

Fax +39051390646

Email afgcicero@cardionet.it 
We searched for all references available on PubMed and EMBASE using the following keywords: berberine, cholesterol and/or triglycerides, glucose, insulin, blood pressure, and atherosclerosis. We cross-matched the references with those cited in the available papers and included the most relevant in this review.

\section{Berberine sources and chemical characteristics}

Berberine is a plant quaternary ammonium salt from the group of isoquinoline alkaloids (2,3-methylenedioxy9,10-dimethoxyprotoberberine chloride; $\mathrm{C}_{20} \mathrm{H}_{18} \mathrm{NO}_{4}^{+}$) with a molar mass of $336.36122 \mathrm{~g} / \mathrm{mol}$. It is highly concentrated in the roots, rhizomes, and stem bark of various plants including Coptis chiensis (Huanglian), Rhizoma coptidis, Hydrastis canadensis (goldenseal), Berberis aquifolium (Oregon grape), Berberis vulgaris (barberry), Berberis aristata (tree turmeric), Tinospora cordifolia, Copthidis rhizome, Arcangelisia flava, and Cortex rhellodendri (Figure 1). ${ }^{8}$ Berberine is yellowcolored, which is why in earlier times Berberis species were used to dye wool, leather, and wood. Wool is still dyed with berberine in Northern India. Under ultraviolet light, berberine shows a strong yellow fluorescence. As a natural dye, berberin has a color index (CI) of $75160 .^{8}$

As a drug, it is traditionally used for its supposed antimicrobial effects and as treatment of diabetes in traditional Chinese, Indian, and Middle-East folk medicine. Its chemical structure has a quaternary base and it is commercially prepared for clinical application as salts such as berberine chloride or berberine sulphate. ${ }^{8}$

\section{Berberine pharmacokinetics}

Berberine has low bioavailability and shows poor absorption through the gut wall $(<5 \%)$ and bowel P-glycoprotein appears to contribute its poor absorption, actively expelling the alkaloid from the lumen mucosal cells. ${ }^{9}$

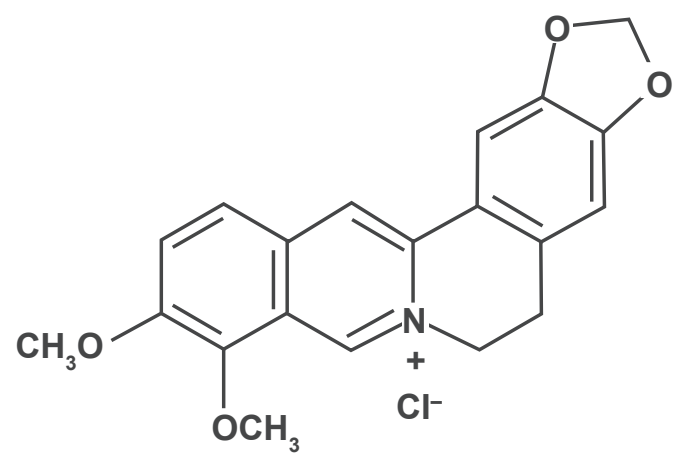

Figure I Chemical structure of berberine.
In a rat noncompartmental model, ${ }^{10}$ unbound berberine is transported to bile through active transportation and it is metabolized by p450 enzyme system in liver, with phase I demethylation and phase II glucuronidation. Berberine has four main metabolites identified in rats: berberrubine, thalifendine, demethyleneberberine, and jatrorrhizine, all of which have glucuronide conjugates. ${ }^{11}$ Intestinal bacterial flora takes a role in enterohepatic circulation of berberine and its conjugated metabolites. ${ }^{10}$ On the other hand, a very small amount of unchanged berberine is eliminated in urine. ${ }^{12}$

As other alkaloids contained in $H$. canadensis extracts (ie, hydrastine and canadine), berberine may inhibit CYP2E1-like ${ }^{13}$ and CYP1A2. ${ }^{14}$ This inhibition is not related to a significant increase in pharmacological interaction since most available drugs are not metabolized by these enzymatic systems.

\section{Berberine antihyperlipidemic effects}

The metabolic effects of berberine have been widely investigated during the last years. In lipid metabolism, the lipid-lowering effect of berberine appears to be mainly due to stabilization of hepatic LDL-C receptor (LDLR) by an extracellular signal-regulated kinase (ERK)dependent pathway and also by increasing transcriptional activity of LDLR promoter by a c-Jun $\mathrm{N}$ terminal kinase (JNK) pathway. ${ }^{15,16}$ Besides, in 3T3L1 cells leptin, transcription factors like sterol regulatory element binding protein-1c (SREBP-1c) and CCAAT enhancer-binding protein- $\alpha$ (C/EBP- $\alpha)$, peroxisome-proliferator activated receptor- $\gamma$ (PPAR- $\gamma)$, fatty acid synthase, acetyl-coenzyme A (acetyl-CoA) carboxylase, acyl-CoA synthase, and lipoprotein lipase are reduced by berberine treatment. ${ }^{17}$ Moreover, in addition to LDLR upregulation, berberine activates 5' adenosine monophosphate (AMP) kinase (AMPK), while blocking the mitogen-activated protein kinase (MAPK)/ERK pathway, resulting in inhibition of lipid synthesis: its action on AMPK is eliminated by MEK inhibitors, suggesting a link between these two pathways (Figure 2). ${ }^{18}$

In rodents, berberine has additive effects to nutrients inhibiting the cholesterol absorption from the bowel such as phytosterols (administered at the dosage of $100 \mathrm{mg} / \mathrm{kg}$ body weight), ${ }^{19}$ or to drugs inhibiting the liver cholesterol synthesis such as simvastatin (administered at the dosage of $6 \mathrm{mg} / \mathrm{kg} /$ day). ${ }^{20}$

The antihyperlipidemic effects of berberine has also been confirmed in humans by some small clinical trials. Kong and 


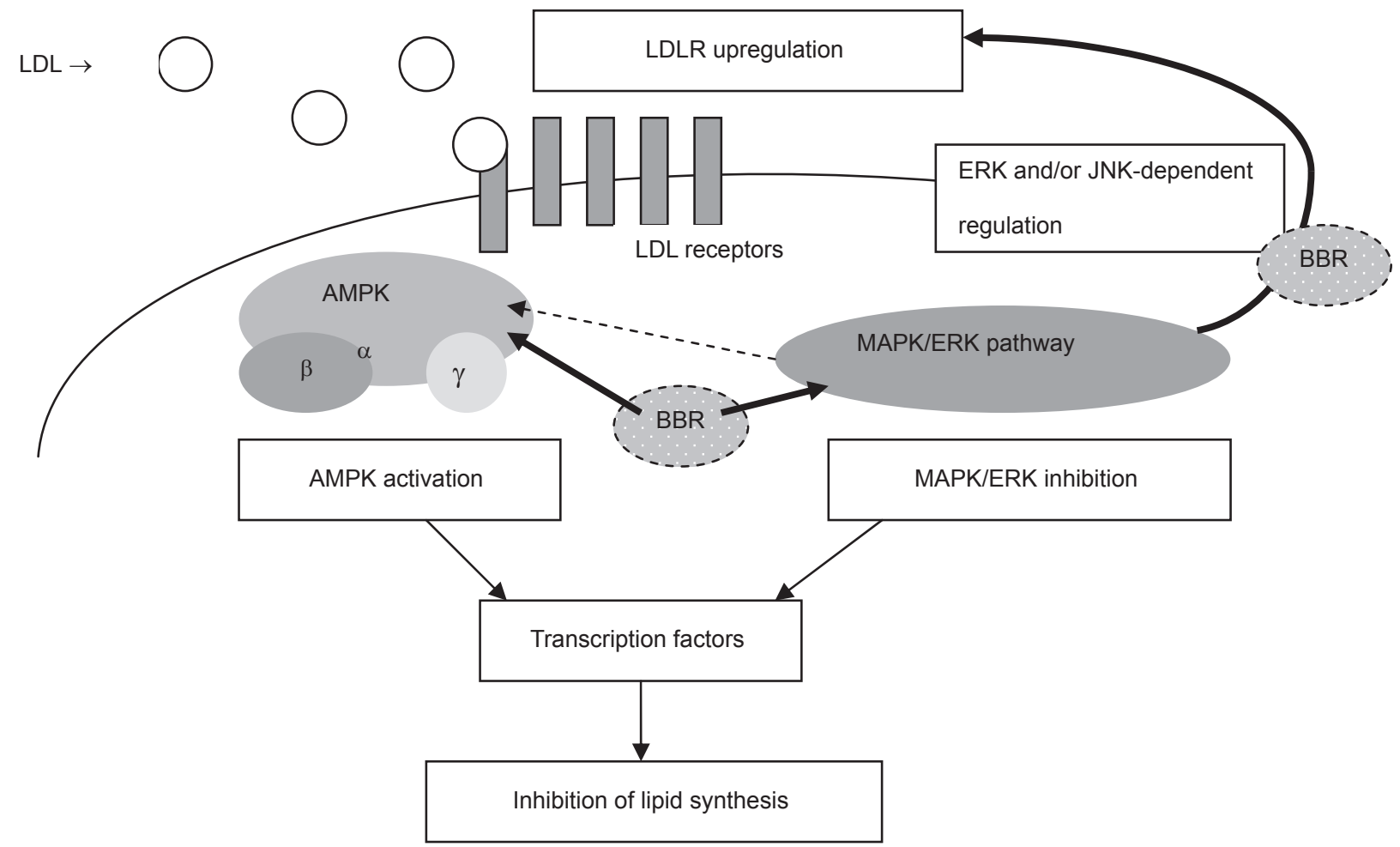

Figure 2 Cellular actions of berberine in lipid metabolism. AMP-activated protein kinase (previously termed as HMG-CoA reductase kinase) plays a key role in cellular energy homeostasis, as a cellular sensor for cellular ATP levels. Binding of AMP to its catalytic $\alpha$ subunit activates the complex that regulates cellular lipid and glucose metabolisms via several transcription factors. With regard to lipid metabolism, AMPK inhibits acetyl CoA carboxylase by activation of $\alpha$ and $\gamma$ subunits, resulting in decreased lipid synthesis. Among three MAPK groups (ERKI/2, P38MAPK, JNK) which are primarily involved in cellular differentiation and cell cycle, JNK is important in LDLR upregulation. MAPK/ERK may also have a link with AMPK pathway in cellular lipid metabolism.

Abbreviations: AMPK, 5' adenosine monophosphate kinase; BBR, berberine; ERK, extracellular signal-regulated kinase; HMG-CoA, 3-hydroxy-3-methylglutaryl-coenzyme A; JNK, c-Jun N terminal kinase; LDL, low-density lipoprotein; LDLR, LDL receptor; MAPK, mitogen-activated protein kinase.

colleagues evaluated the effects of $500 \mathrm{mg}$ berberine twice a day in a hyperlipidemic group of 32 Asian patients without any other drug use for three months and compared the results with 11 patients using placebo. Berberine significantly reduced the total cholesterol by $29 \%$, triglycerides by $35 \%$, and LDL-C by $25 \%{ }^{21}$ These results have been then confirmed in a larger trial carried out on 116 hyperlipidemic type 2 diabetic patients randomized to treatment with berberine $0.5 \mathrm{~g}$ thrice daily or placebo. Beyond a similar decrease in plasma lipids, the berberine-treated patients also experienced a significant decrease in glycohemoglobin, fasting and two-hour postprandial glucose levels compared with the placebo group. ${ }^{22}$

Moreover, the antihyperlipidemic effect of berberine was observed to be synergistic with other nutraceuticals inhibiting cholesterol synthesis such as monakolins and policosanols. In a small clinical trial carried out on 40 Caucasian hyperlipidemic subjects randomized to berberine alone $500 \mathrm{mg}$ /day or berberine $500 \mathrm{mg}$ associated with policosanol $10 \mathrm{mg}$ and red yeast extract $3 \mathrm{mg} /$ day for four weeks, the reduction in triglycerides was $26 \%$ in the combination group and $22 \%$ in the berberine group, and reduction of LDL-C was $20 \%$ in the berberine group and $25 \%$ in the combination group. ${ }^{23}$

\section{Effects of berberine on insulin resistance and fatty acids metabolism}

Beyond a direct and impressive effect of berberine on lipid metabolism, recent preclinical and clinical evidence suggest that it has also a strong impact on glucose homeostasis.

In fact, in cultured human liver cells and rat skeletal muscle, berberine increases insulin receptor mRNA expression through protein kinase C-dependent activation of its promoter. ${ }^{24}$

It has been observed in cultured cells that berberine acts as an insulin-sensitizing agent, ${ }^{25}$ therefore its activity has been compared with metformin in different animal models. In a rat model of type 2 diabetes, berberine showed better fasting plasma glucose and LDL-C lowering and better homeostasis 
model assessment of insulin resistance (HOMA-IR) than metformin by a mechanism involving retinol binding protein-4 (RBP-4) and glucose transporter-4 (GLUT-4). ${ }^{26}$ However, in another study, berberine was not inferior to metformin as an insulin-sensitizer. ${ }^{27}$

It is possible that berberine does not act simply as an insulin-sensitizing agent, but that it may also interact directly with the pancreas. In fact, in streptozocin-induced diabetic rats, berberine administrated at the doses of $120 \mathrm{mg} / \mathrm{kg} /$ day for five weeks was associated to an increase in glucagon-like peptide-1 (GLP-1) levels in plasma and intestine, in plasma insulin levels, and in the number of pancreatic beta cells. ${ }^{28}$ Furthermore, berberine inhibits sucrase and maltase activity similarly to acarbose, and since berberine has low bioavailability, its antihyperglycemic effects may be related to its intestinal actions. ${ }^{7}$

Some evidence suggest that berberine also acts as a secretagogue agent which was demonstrated in diabetic rats where the this effect was compared with that of the sulphonylurea glibenclamide. ${ }^{29}$ In this test, berberine enhances glucose-stimulating insulin secretion in a dose-dependent manner, increasing both mRNA and protein expressions of hepatic nuclear factor $4 \alpha$, and glycokinase activity, providing insulinotropic effect different from sulfonylureas. A dosedependent insulin secretory effect was also observed by other authors, together with a favorable impact on plasma lipid levels. ${ }^{30}$ However, contrasting results are available since no secretagogue action in the betaTC3 cell line was observed, ${ }^{7}$ while a recent study observed that berberine acutely inhibits insulin secretion in MIN6 cells and rat islets. ${ }^{31}$ It is more probable that berberine has a protective effect for diabetes through increasing beta cell regeneration, antioxidant enzyme activity, and decreasing lipid peroxidation. ${ }^{32}$

Other mechanisms of action have also been suggested to explain the complex berberine effect on glucose homeostasis. Some preclinical evidence shows that berberine inhibits mitochondrial function by inhibition of mitochondrial respiratory complex I, ${ }^{33}$ stimulation of glycolysis, activation of AMPK pathway, suppression of adipogenesis, antiobesity effects, and induction of LDLR expression. These are important mechanisms for insulin resistance and lipid metabolism..$^{34,35}$

In the 3T3-L1 adipocytes model of insulin resistance, berberine reverses $1 \mathrm{kB}$ kinase beta (IKKbeta) Ser(181) and insulin receptor substrate 1 (IRS-1) Ser(307) phosphorylation and improves insulin-stimulated glucose transport and reverses free fatty acid (palmitic acid in this study)-induced insulin resistance. ${ }^{36}$ However, in another study carried out on the same cell lines, berberine did not augment either IRS-1, nor insulin receptor thyrosine phosphorylation, but it increased GLUT-4 levels in both normal and insulin-resistant cells and AMPK activity which is related to GLUT-1-mediated glucose uptake. ${ }^{37}$ Inhibition of mitochondrial glucose oxidation by berberine and increased AMP/adenosine triphosphate (ATP) ratio causes AMPK activation and glycolysis stimulation. ${ }^{38}$

Therefore, Zhou and colleagues showed that, unlike insulin, berberine-induced glucose uptake of 3T3L1 adipocytes is not inhibited by phosphatidylinositol 3-kinase inhibitor or p38 MAPK inhibitor. Berberine does not induce Akt phosphorylation in opposition to insulin, but its action is totally inhibited by the thyrosine kinase inhibitor genistein. Finally, berberine increases AMPK and acetyl CoA carboxylase phosphorylation. ${ }^{39}$ Since the berberine-induced glucose uptake is inhibited both by AMPK inhibitor (compound C) and p38 MAPK inhibitor (SB202190), berberine uses an AMP-AMPK-p38 MAPK pathway and this may account also for its antihyperlipidemic effects. ${ }^{40}$ Berberine increases PPAR- $\alpha / \Delta$ expression and reduced PPAR- $\gamma$ expression in liver of diabetic rat to near control expression. ${ }^{41}$ In cellular models, the decrease in PPAR- $\gamma$ mRNA transcription is associated with an inhibition of the adipocyte differentiation. ${ }^{42,43}$ This global action on the modulation of PPARs could at least partly explain the broad range of berberine metabolic activities on glucose and lipid metabolism. The effects of berberine on glucose metabolism are summarized on Figure 3.

Beyond the large preclinical literature, data on human glucose metabolism are really preliminary. However, in a recent study carried out on subjects affected by type 2 diabetes, the assumption of berberine $500 \mathrm{mg}$ three times a day was associated with a significant reduction in hemoglobin- $\alpha 1$ (HbA1) $(-2 \%)$, fasting plasma glucose $(-44 \%)$, postprandial glucose $(-45 \%)$, fasting plasma insulin $(-28 \%)$, and HOMA-IR index (-44.7\%). ${ }^{44}$ In this study, berberine also significantly reduced plasma total and LDL-C levels.

\section{Vascular and antihypertensive effects of berberine}

Vasorelaxant effects of berberine have been observed in different rat models. ${ }^{45-47}$ At low concentrations $\left(<1 \times 10^{-6} \mathrm{M}\right)$, berberine-mediated aortic relaxation appears to be dependent on endothelium, but at higher concentrations appears to be independent of intact endothelium. ${ }^{48}$ So, it is probable that berberine acts both on endothelium and underlying smooth muscle cells. ${ }^{49}$ Other mechanisms suggested to be involved in the vasorelaxant effect of berberine are 


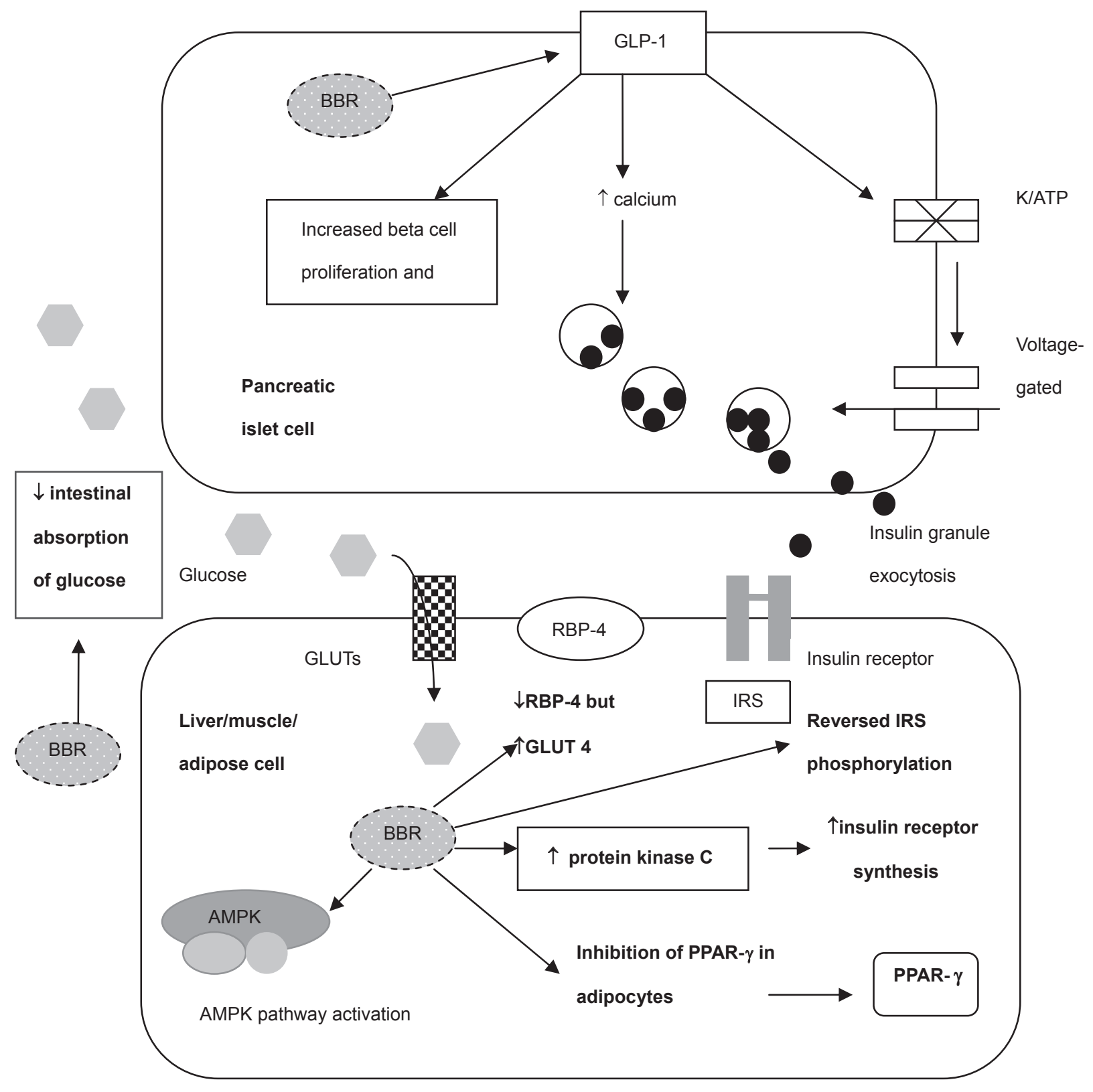

Figure 3 Effects of berberine on glucose metabolism. Berberine affects glucose metabolism increasing insulin secretion, stimulating glycolysis, suppressing adipogenesis, inhibiting mitochondrial function, activating the AMPK pathway, and increasing glycokinase activity. Berberine also increases GLUT-4 and GLP-I levels. GLP-I receptors are important in islet cell survival: upon their activation, adenylyl cyclase is activated and cAMP generated, leading to activation of second messenger pathways and closure of ATP-dependent $\mathrm{K}^{+}$channels. Increased intracellular potassium causes depolarisation, and calcium influx through the voltage dependent calcium channels occurs. This intracellular Ca ${ }^{++}$increase stimulates the migration and exocytosis of the insulin granules. In glucose consuming tissues, such as adipose, liver or muscle cells, berberine affects both GLUT-4 and RBP-4 in favour of glucose uptake into cell, stimulates glycolysis by AMPK activation and also have effects on PPAR- $\gamma$ molecular targets and phosphorylation of IRS-I, finally resulting in decreased insulin resistance.

Abbreviations: AMPK, 5' adenosine monophosphate kinase; ATP, adenosine triphosphate; cAMP, cyclic adenosine monophosphate; GLP-I, glucagon-like peptide- I; GLUT-4, glucose transporter-4; IRS, insulin receptor substrate I; PPAR- $\gamma$, peroxysome proliferator activator receptors gamma; RPB-4, retinol-binding protein-4.

an angiotensin-converting enzyme (ACE) inhibitory effect and direct release of NO/cGMP from rat aortic rings, ${ }^{50} \alpha_{1-}$ adrenoreceptor antagonistic action in rat and rabbit aorta, ${ }^{51}$ increased sensitivity to the acetylcholine action, ${ }^{46}$ activation of $\mathrm{K}^{+}$channels, and the inhibition of intracellular calcium release, blocking of L-type calcium channels. ${ }^{52}$ Berberine increases expression of endothelial nitric oxide synthase (eNOS) mRNA and inhibits expression of inducible nitric oxide synthase (iNOS) mRNA in gastric tissue also in studies on ethanol-induced gastric ulcer in mice. ${ }^{53}$ In isolated rat thoracic aorta, prior exposure to berberine attenuated angiotensin-1-induced contraction and increases NO and cGMP 1 with a half maximal inhibitory concentration $\left(\mathrm{IC}_{50}\right)$ value of $42 \mathrm{mg} / \mathrm{mL}(125 \mu \mathrm{M}){ }^{54}$ 
Activation of tetrapentylammonium-, 4-aminopyridine- and $\mathrm{Ba}^{2+}$-sensitive $\mathrm{K}^{+}$channels, inhibition of intracellular $\mathrm{Ca}^{2+}$ release from caffeine-sensitive pools, or a direct relaxant effect, are also likely responsible for the berberine-induced endothelium-independent relaxation. ${ }^{55}$

The vasodilatator effects of berberine are not observed at low concentrations (below $1 \times 10^{-6} \mathrm{M}$ ) on methylene blue-pretreated rat aorta, but aortic relaxation was observed at higher concentrations irrespective of such nitric oxide inhibitors. ${ }^{56}$

Blood pressure increase could also been prevented by a nephroprotective effect. In a model of rat diabetic nephropathy, oral administration of berberine at $200 \mathrm{mg} / \mathrm{kg} /$ day doses for 12 weeks improved the kidney-to-body weight ratios, glomerular area and volume, kidney tests (serum creatinine, serum uric acid, serum urea, urine protein for 24 hours), and increased serum superoxide dismutase and decreased malonydialdehyde and aldose reductase levels. ${ }^{57}$

Berberine also has some vascular-protecting action that could preserve the arterial functionality from damage and keep the vessels more reactive and elastic. In fact, berberine inhibits platelet-derived growth factor (PDGF)-induced vascular smooth muscle cell growth via activation of AMPK/ p53/p21(Cip1) signaling while activating Ras/Rac1/Cyclin $\mathrm{D} / \mathrm{Cdks}$, and suppressing PDGF-stimulated migration by Rac1 and Cdc42 inhibition, finally causing antiproliferative and antimigratory effects. ${ }^{58}$ In rat glomerular mesangial cells, berberine inhibits fibronectin and collagen synthesis partly via a p38 MAPK pathway. ${ }^{59}$ It also prevents the migration and regrowth of smooth muscle cells to the mechanically traumatized site by inactivating the MAPK/ERK/early growth response gene 1 (Egr1) signaling pathway, decreasing Erg1, cFos, cyclin-D, and platelet-related growth factor A (PDGF-A) levels. ${ }^{60}$ Activation of ERK1,2 pathway was also demonstrated by its inhibition of lysophosphatidylcholine-stimulated vascular smooth muscle cell proliferation and migration. ${ }^{61}$

Concerning human data, in a study carried out on 20 volunteers, $400 \mathrm{mg}$ berberine three times a day for a month induced upregulation of the number and function of erythrocyte progenitor cells due to NO production. ${ }^{62}$ One month's treatment with berberine $(400 \mathrm{mg} /$ day, three times a day) in 15 healthy volunteers induced mobilization of circulating endothelial progenitor cells with CD34/KDR double positivity in small arteries. ${ }^{63}$

\section{Direct effects of berberine on heart}

Berberine does not have only indirect myocardium protective effects by modulating lipid metabolism, glucose homeostasis, and blood pressure, but it also directly acts on the heart at different levels.

In fact, berberine has a sympathetic activity-modulated effect on myocardium. In rats with experimentally induced cardiac hypertrophy by suprarenal aortic constriction, berberine decreased plasma noradrenaline and adrenaline levels and adrenaline in ventricular tissue, improved cardiac contractility with a shortened time to reach the maximum rate from beginning of contraction and reduced the size of left ventricular myocardium. ${ }^{64,65}$ In a dog ischemic heart failure model, intravenous berberine administration increased cardiac output, decreased left ventricular end diastolic pressure and systemic vascular resistance. ${ }^{66}$ This activity was also confirmed in other animal models. ${ }^{49}$

Berberine increased high energy phosphate in heart failure and prevented ventricular fibrillation due to its effects on potassium channels, ${ }^{67,68}$ increased intracellular calcium, ${ }^{69}$ suppressed delay of depolarization partly due to sodium influx..$^{70}$ Berberine blocked ATP-sensitive and voltage-sensitive $\mathrm{K}^{+}$(ATP) channels and caused shortening of action potential duration and effective refractory period, thus it mainly has a class III antiarrythmic effect as shown in different animal models. ${ }^{71}$

Berberine reduced creatine phosphokinase release in reoxygenation period in rat myocytes and decreased the morphologic features related with myocardial injury, which reduced lactate dehydrogenase and methylene dioxyamphetamine levels and the apoptosis rate. ${ }^{72}$

Examination of hemodynamic parameters in humans reveals similar results with increased cardiac index, increased left ventricular ejection fraction, decreased systemic and pulmonary vascular resistance and left ventricular end-diastolic pressures. ${ }^{73}$ In a clinical trial carried out on chronic heart failure patients, berberine decreased frequency and complexity of ventricular premature complexes and increased the left ventricular ejection fraction. ${ }^{74}$ In 24-48-hour ambulatory monitoring of 100 patients with ventricular tachyarrhythmia, berberine caused $50 \%$ or greater reduction in ventricular premature contractions in $62 \%$ of patients and $90 \%$ or more reduction in $38 \%$ of patients. ${ }^{75}$

\section{Other berberine activities with potential relevance in cardiovascular disease prevention}

Some studies show that berberine has a significant antiplatelet effect, ${ }^{76}$ explained by inhibition of arachidonic acid metabolism and calcium influx, ${ }^{77}$ but also by a partial agonistic effect on platelet $\alpha 2$ adrenoreceptors. ${ }^{76}$ Berberine inhibited thromboxane 
synthesis induced by collagen, adenosine diphosphate and arachidonic acid, and it might inhibit arachidonic acid metabolism in platelets and endothelial cells. ${ }^{73}$ On the other hand, recent evidence suggests that berberine can also have prothrombotic effect-enhancing tissue factor activity. ${ }^{78}$

Another pharmacological effect of berberine that could be relevant in atherosclerosis prevention is its anti-inflammatory effect. Berberine probably inhibits cycloxygenase-2 (COX-2) via the ERK1/2 signaling pathway and, in high doses, via the JNK pathway in human peripheral blood monocytes. ${ }^{79}$ However, the anti-inflammatory effects of berberine may also be mediated through nuclear factor- $\kappa \mathrm{B}$ activation pathway inhibition which modulates the transcription of genes codifying for COX-2, matrix metalloprotese-9, cyclin D-1, and survivin. ${ }^{80}$ Moreover, berberine inhibits matrix metalloprotein-9 and interleukin-6 (IL-6) in normal human keratocytes and shows anti-inflammatory effects on skin. ${ }^{81}$ Berberine downregulated the mRNA of tumor necrosis factor- $\alpha$, IL-6, C-reactive protein, and haptoglobulin in 3T3L1 adipocytes. ${ }^{82}$ Similar results have also been observed in macrophages. ${ }^{83}$ This effect could be mediated by an activation of PPAR- $\gamma$ mediated by an increase in adipophilin, but most researchers suggest that Berberine acts more as a PPAR- $\gamma$ inhibitor than as an activator, at least in adipocytes, hepatocytes, and retinal cells. This difference remains to be explained.

In rabbit corpus cavernosum smooth muscle cell cultures, berberine inhibits the damaging effects of $\mathrm{H}_{2} \mathrm{O}_{2}$ by increased cell viability, increased nitric oxide, and superoxide dismutase (SOD) activity, decreased lactate dehydrogenase release and the malondialdehyde content of the tissue. ${ }^{84}$ The antioxidant effect of berberine has also been demonstrated in human umbilical endothelial cells, probably in relative electrophoretic mobility of oxidized-LDL, fragmentation of apolipoprotein $\mathrm{B}$ and malonyldialdehyde production, inhibition of caspase 3 activation and cytochrome $\mathrm{C}$ release. ${ }^{85}$ Dose-dependent increase in SOD by berberine was then confirmed in rats together with reduction in $\alpha$-smooth muscle actin ( $\alpha$-SMA) and transforming growth factor- $1 \beta$ (TGF-1 $\beta$ ), liver steatosis and necrosis in a rat liver fibrosis model.$^{86}$ Other studies on rodent hepatocytes showed reduced oxidative stress, higher level of DNA repair induction, reduced histopathological evidence of tissue injury with berberine treatment. ${ }^{87}$ This effect, associated to the metabolic ones, could suggest its potential usefulness in the management of the nonalcoholic steatoepatitis (NASH), an emergent cardiovascular disease risk factor.

\section{Berberine tolerability and safety}

The median lethal dose $\left(\mathrm{LD}_{50}\right)$ of berberine sulfate is $25 \mathrm{mg} / \mathrm{kg}$ in mice, but for Berberis vulgare, is moderately high $\left(\mathrm{LD}_{50}=2.6 \pm 0.22 \mathrm{~g} / \mathrm{kg}\right.$ bodyweight in mice $){ }^{88}$ These data support the use of highly purified and concentrated berberine formulation only.

Standard doses of berberine are usually well tolerated and eventual adverse events are rare and mild. On the contrary, high doses have been associated with arterial hypotension, dyspnea, flu-like symptoms, gastrointestinal discomfort, constipation, and cardiac damage. ${ }^{34}$ The most studied side effects are those in the gastrointestinal system. Berberine and derivatives can produce gastric lesions. ${ }^{89}$ As shown by determination of small intestinal transit time (SITT) measurements by sorbitol and breath hydrogen test (BHT), berberine delays SITT, and this may account for a part of its gastrointestinal side effects (but also of its antidiarrheal one). ${ }^{90}$

The main safety issue of berberine involves the risk of some pharmacological interaction. In fact, berberine displaces bilirubin from the albumin about 10-fold more than phenylbutazone, thus any herb containing large amounts of berberine should be avoided in jaundiced infants and pregnant woman. ${ }^{91}$ Berberine displaces warfarin, thiopental, and tolbutamide from their protein-binding sites, increasing their plasma levels. ${ }^{92}$

Berberine can markedly increase blood levels of cyclosporine A because of CYP3A4 and P-glycoprotein inhibition in the liver and gut wall, respectively, and because of an increase in gastric-emptying time causing increased cyclosporine A bioavailability and reduced metabolism. ${ }^{93}$ In renal transplant recipients who take cyclosporine $3 \mathrm{mg} / \mathrm{kg}$ twice daily, the coadministration of berberine $(0.2 \mathrm{~g} /$ day for three times a day for three months) increases the mean cyclosporine A area under the curve by $34.5 \%$ and its mean half-life by 2.7 hours. $^{94}$

In rats, P-glycoprotein and organic cation transport inhibit active berberine efflux since coadministration of berberine and cyclosporine (a P-glycoprotein inhibitor) or quinidine (both an organic cation transport and P-glycoprotein inhibitor) at the same dosage significantly decreased the berberine amount in bile. In addition, berberine was metabolized in the liver with phase I demethylation and phase II glucuronidation, as identified by high = pressure liquid chromatography/tandem mass spectrometry. The phase I metabolism of berberine was partially reduced by SKF-525A (proadifen, a cytochrome $\mathrm{P} 450$ inhibitor) treatment, but the phase II glucuronidation of berberine was not obviously affected by probenecid 1glucuronidation inhibitor). ${ }^{10}$

Berberine is also a subtrate of the organic cation transporter 1 (OCT1, SLC22A1) in the basolateral membrane and MDR1 
P-glycoprotein (MDR1 P-gp, ABCB1), an ATP-dependent efflux pump for organic cations, in the apical membrane..$^{95}$

Moreover, it was observed with flow cytometry that a 24-hour berberine treatment upregulated the multidrug-resistant transporter (P-gp-170) expression in two oral (KB, OC2), two gastric (SC-M1, NUGC-3), and two colon (COLO 205, CT 26) cancer cell lines. Decreased retention of rhodamine 123 was observed in berberine-treated cells as compared to vehicle control. Pretreatment of cells with 32 microM berberine for 24 hours prior to Paclitaxel treatment resulted in increased viability as compared to that of Paclitaxel-treated cells. Moreover, pretreatment of cells with berberine prior to Paclitaxel blocked the Paclitaxelinduced cell cycle responses and morphological changes. These results together suggest that berberine modulated the expression and function of P-gp-170 that leads to reduced response to Paclitaxel in digestive track cancer cells. ${ }^{96}$

Even if the main mechanism of pharmacological interaction of berberine involve CYP3A4 and intestinal P-glycoprotein, it also inhibits CYP1A1, so potentially interacting with drugs metabolized by this cytochrome isophorm as well. ${ }^{97}$

\section{Conclusion}

A large part of the literature on berberine is difficult to access since it was published in Chinese and this limited our possibility to directly access to some interesting scientific data. However, on the basis of the evidence cited above, we can conclude that numerous preclinical studies and some well-carried out clinical trials strongly support the potential use of berberine as a powerful insulin-sensitizing agent with relevant antihyperlipidemic effects and vascular protective action. Further long-term randomized clinical trials have to be carried out in order to better delineate the clinical indications and the safety profile of berberine.

\section{Disclosures}

The authors report no conflicts of interest in this work.

\section{References}

1. Müller-Nordhorn J, Binting S, Roll S, Willich SN. An update on regional variation in cardiovascular mortality within Europe. Eur Heart J. 2008;29(10):1316-1326.

2. Gaziano TA. Reducing the growing burden of cardiovascular disease in the developing world. Health Aff (Millwood). 2007;26(1):13-24.

3. Baigent C, Keech A, Kearney PM, et al; Cholesterol Treatment Trialists' (CTT) Collaborators. Efficacy and safety of cholesterol-lowering treatment: prospective meta-analysis of data from 90,056 participants in 14 randomised trials of statins. Lancet. 2005;366(9493):1267-1278.

4. Fruchart JC, Sacks F, Hermans MP, et al. The Residual Risk Reduction Initiative: a call to action to reduce residual vascular risk in patients with dyslipidemia. Am J Cardiol. 2008;102(10 Suppl):1K-34K.
5. Sénécal M, Fodor G, Gagné C, et al. Limitations of statin monotherapy for the treatment of dyslipidemia: a projection based on the Canadian lipid study - observational. Curr Med Res Opin. 2009;25(1):47-55.

6. Jacobson TA. Toward "pain-free" statin prescribing: clinical algorithm for diagnosis and management of myalgia. Mayo Clin Proc. 2008;83(6):687-700.

7. Cicero AFG, Ertek S. Natural sources of antidyslipidaemic agents: is there an evidence-based approach for their prescription? Med J Nutr Metab. 2008;1(2):85-93.

8. Birdsall TC, Kelly GS. Berberine: Therapeutic potential of an alkaloid found in several medicinal plants. Altern Med Rev. 1997;2:94-103.

9. Pan GY, Wang GJ, Liu XD, Fawcett JP, Xie YY. The involvement of p-glycoprotein in berberine absorption. Pharmacol Toxicol. 2002;91:193-197.

10. Tsai PL, Tsai TH. Hepatobiliary excretion of berberine. Drug Metab Dispos. 2003;32:405-412.

11. Zuo F, Nakamura N, Akao T, Hattori M. Pharmacokinetics of berberine and its main metabolites in conventional and pseudo germ-free rats determined by liquid chromatography/ion trap mass spectrometry. Drug Metab Dispos. 2006;34:2064-2072.

12. Chen CM, Chang HC. Determination of berberine in plasma, urine and bile by high performance liquid chromatograpy. J Chromatogr. 1995;665:117-123.

13. Raner GM, Cornelious S, Moulick K, Wang Y, Mortenson A, Chech NB. Effects of herbal products on human cytochrome P450(2E1) activity. Food Chem Tox. 2007;45:2359-2365.

14. Zhao X, Zhang JJ, Wang X, Bu XY, Lou YQ, Zhang GL. Effect of berberine on hepatocyte proliferation inducible nitric oxide synthase expression, cyrochrome $4502 \mathrm{E} 1$ and $1 \mathrm{~A} 2$ activities in diethylnitrosamine- and Phenobarbital-treated rats. Biomed Pharmacother. 2008;62:567-572.

15. Abidi P, Zhou Y, Jiang JD, Liu J. Extracellular signal regulated kinase - dependent stabilization of hepatic low density lipoprotein receptor mRNA by herbal medicine berberine. Arterioscler Thromb Vasc Biol. 2005;25:2170-2176.

16. Lee S, Lim HJ, Park JH, Lee KS, Jang Y, Park HY. Berberine induced LDLR up-regulation involves JNK pathway. Biochem Biophy Res Commun. 2007;362:853-857.

17. Choi BH, Ahn IS, Kim YH, et al. Berberine reduces the expression of adipogenic enzymes and inflammatory molecules of 3T3L1 adipocyte. Exp Mol Med. 2006;38:599-605.

18. Brusq JM, Ancellin N, Grondin P, et al. Inhibition of lipid synthesis through activation of AMP kinase: an additional mechanism for the hypolipidemic effects of berberine. J Lipid Res. 2006;47: $1281-1288$

19. Jia X, Chen Y, Zidichousky J, Zhang J, Sun C, Wang Y. Co-administration of berberine and plant sterols synergistically reduces plasma cholesterol in rats. Atherosclerosis. 2009;201(1):101-107.

20. Kong WJ, Wei J, Zuo ZY, et al. Combination of simvastatin with berberine improves the lipid-lowering efficacy. Metabolism. 2008;57:1029-1037.

21. Kong W, Wei J, Abidi P, et al. Berberine is a novel cholesterol lowering drug working through a unique mechanism distinct from statins. Nat Med. 2004;10:1344-1351.

22. Zhang Y, LI X, Zou D, et al. Treatment of type 2 diabetes and dyslipidemia with the natural plant alkaloid berberine. J Clin Endocrinol Metab. 2008;93:2559-2565.

23. Cicero AF, Rovati LC, Setnikar I. Eulipidemic effects of berberine administered alone or in combination with other natural cholesterollowering agents. A single-blind clinical investigation. Arzneimittelforschung. 2007;57:26-30.

24. Kong WJ, Zhang H, Song DQ, et al. Berberine reduces insulin resistance through protein kinase C-dependent up-regulation of insulin receptor expression. Metabolism. 2009;58:109-119.

25. Ko BS, Choi SB, Park SK, Jang JS, Kim YE, Park S. Insulin sensitizing and insulinotropic action of berberine from Cortidis rhizoma. Biol Pharm Bull. 2005;28:1431-1437. 
26. Zhang W, Xu YC, Guo FJ, Meng Y, Li ML. Antidiabetic effects of cinnamaldehyde and berberine and their impacts on retinol binding protein 4 expression in rats with type 2 diabetes mellitus. Chin Med J. 2008;121:2124-2128.

27. Yin J, Hu R, Chen M, Tang J, Li F, Yang Y, Chen J. Effects of berberine on glucose metabolism in vitro. Metabolism. 2002;51:1439-1443.

28. Lu SS, Yu YL, Zhu HJ, et al. Berberne promotes glucagons like peptide-1(7-36 amide) secretion in streptozocin-induced diabetic rats J Endocrinol. 2009;200(2):159-165.

29. Wang ZQ, Lu FE, Leng SH, et al. Facilitating effects of berberine on rat pancreatic islets through modulating hepatic nuclear factor 4 alpha expression and glucokinase activity. World J Gastroenterol. 2008;14:6004-6011.

30. Leng S, Lu F, Xu L. Therapeutic effects of berberine in impaired glucose tolerance rats and its influence on insulin secretion. Acta Pharmacol Sin. 2004;25:496-502.

31. Zhou L, Wang X, Shao L, et al. Berberine acutely inhibits insulin secretion from beta-cells through 3',5'-cyclic adenosine 5'-monophosphate signaling pathway. Endocrinology. 2008;149(9):4510-4518.

32. Zhou J, Zhou S, Tang J, et al. Protective effect of berberine on beta cells in streptozotocin- and high-carbohydrate/high-fat diet-induced diabetic rats. Eur J Pharmacol. 2009;606(1-3):262-268.

33. Turner N, Li JY, Gosby A, et al. Berberine and its more biologically available derivative, dihydroberberine, inhibit mitochondrial respiratory complex I: a mechanism for the action of berberine to activate AMP-activated protein kinase and improve insulin action. Diabetes. 2008;57:1414-1418.

34. Imanshahidi M, Hosseinzadeh H. Pharmacological and therapeutic effects of Berberis vulgaris and its active constituent, berberine Phytother Res. 2008;22:999-1012.

35. Yin J, Zhang H, Ye J. Traditional Chinese medicine in treatment of metabolic syndrome. Endocr Metab Immune Disord Drug Targets. 2008;8:99-111.

36. Yi P, Lu FE, Xu LJ, Chen G, Dong H, Wang KF. Berberine reverses free-fatty-acid-induced insulin resistance in 3T3-L1 adipocytes through targeting IKKbeta. World J Gastroenterol. 2008;14:876-883.

37. Kim SH, Shin EJ, Kim ED, Bayaraa T, Frost SC, Hyun CK. Berberine activated GLUT-1 -mediated glucose uptake in 3T3-L1 adipocytes Bio Pharm Bull. 2007;30:2120-2125.

38. Yin J, Gao Z, Liu D, Liu Z, Ye J. Berberine improves glucose metabolism through induction of glycolysis. Am J Physiol Endocrinol Metab. 2008;294:E148-E156.

39. Zhou L, Yang Y, Wang X, et al. Berberine stimulates glucose transport through a mechanism distinct from insulin. Metabolism. 2007;56 405-412.

40. Cheng Z, Pang T, Gu M, et al. Berberine stimulated glucose uptake in L6 myotubes includes both AMPK and p 38 MAPK. Biochim Biophys Acta. 2006;1760:1682-1689.

41. Zhou JY, Zhou SW, Zhang KB, et al. Chronic effects of berberine on blood, liver glucolipid metabolism and liver PPARs expression in diabetic hyperlipidemic rats. Biol Pharm Bull. 2008;31(6): 1169-1176.

42. Huang C, Zhang Y, Gong Z, et al. Berberine inhibits 3T3L1 adipocyte differentiation through the PPARgamma pathway. Biochem BiophysRes Comun. 2006;348:571-578.

43. Wang SH, Wang WJ, Wang XF, Chen W. Effects of Astragalus polysaccharides and berberine on carbohydrate metabolism and cell differentiation in 3T3-L1 adipocytes. Zhongguo Zhong Xi Yi Jie He Za Zhi. 2004;24:926-928.

44. Yin J, Xing H, Ye J. Efficacy of berberine in patients with type 2 diabetes mellitus. Metabolism. 2008;57:712-717.

45. Fatehi-Hassanabad Z, Zafarzadeh M, Tarhini A, Fatehi M. The antihypertensive and vasodilator effects of aqueous extract from Berberis vulgaris fruit on hypertensive rats. Phytother Res. 2005;19: 222-225.

46. Peychev L. Pharmacological investigation on the cardiovascular effects of Berberine vulgaris on tested animals. Pharmacia. 2005;52:118-121.
47. Chun YT, Yip TT, Lu KL, Kong YC, Sankawa U. A biochemical study on hypotensive effects of berberine in rats. Gen Pharmacol. 1979; 10:177-182.

48. Wong KK. Mechanism of the aortic relaxation induced by low concentrations of berberine. Planta Med. 1998;64:756-757.

49. Ko WH, Yao XQ, Lau CW, et al. Vasorelaxant and antiproliferative effects of berberine. Eur J Pharmacol. 2000;399:187-196.

50. Kang DG, Sohn EJ, Kwon EK, Han JH, Oh H, Lee HS. Effects of berberine on angiotensin-converting enzyme and NO/cGMP system in vessels. Vasc Pharmacol. 2003;39:281-286.

51. Olmez E, Ilhan M. Evaluation of the alpha-adrenoceptor antagonistic action of berberine in isolated organs. Arzneimittelforschung. 1992; 42:1095-1097.

52. Chiou WE, Yen MH, Chen CF. Mechanism of vasodilatory effect of berberine in rat mesenteric artery. Eur J Pharmacol. 1991;204:35-40.

53. Pan LR, Tang Q, Fu Q, Hu BR, Xiang JZ, Qian JQ. Roles of nitric oxide in protective effect of berberine in ethanol-induced gastric ulcer mice. Acta Pharmacol Sin. 2005;26:1334-1338

54. Kang DG, Sohn EJ, Kwon EK, Han JH, Oh H, Lee HS. Effects of berberine on angiotensin-converting enzyme and NO/cGMP system in vessels. Vascul Pharmacol. 2002;39:281-286.

55. Ko WH, Yao XO, Lau CW, et al. Vasorelaxant and antiproliferative effects of berberine. Eur J Pharmacol. 2000;399:187-196.

56. Wong KK. Mechanism of the aortic relaxation induced by low concentrations of berberine. Planta Med. 1998;64:756-757.

57. Liu WH, Hei ZQ, Nie H, et al. Berberine ameliorates renal injury in streptozocin-induced diabetic rats by suppression of both oxidative stress and aldose reductase. Chin Med J. 2008;121:706-712.

58. Liang KW, Yin SC, Ting CT, et al. Berberine inhibits platelet-derived growth factor-induced growth and migration partly through an AMPKdependent pathway in vascular smooth muscle cells. Eur J Pharmacol. 2008;590:343-354.

59. Liu W, Tang F, Deng Y, et al. Berberine reduces fibronectin and collagen accumulation in rat glomerular mesengial cells cultured under high glucose condition. Mol Cell Boichem. 2009;325(1-2):99-105.

60. Liang KW, Ting CT, Yin SC, et al. Berberine suppresses MEK/ ERK-dependent Egr-1 signalling pathway and inhibits vascular smooth muscle regrowth after in vitro mechanical injury. Biochem Pharmacol. 2006;71:806-817.

61. Cho BJ, Im EK, Kwon JH, et al. Berberine inhibits the production of lysophosphatidylcholine-induced reactive oxygen species and the ERK1,2 pathway in smooth muscle cells. Mol Cells. 2005;20: 429-434.

62. Xu MG, Wang JM, Chen L, Wang Y, Yang Z, Tao J. Berberine-induced upregulation of endothelial progenitor cells in related to nitric oxide production in healthy subjects. Cardiology. 2008;112:279-286.

63. Xu MG, Wang JM, Chen L, Wang Y, Yang Z, Tao J. Berberine-induced mobilization of circulating endothelial progenitor cells improves human small artery elasticity. J Hum Hypertens. 2008;22:389-393.

64. Hong Y, Hui SS, Chan BT, Hou J. Effect of berberine on catecholamine levels in rats with experimental cardiac hypertrophy. Life Sci. 2003; 72:2499-2507.

65. Hong Y, Hui SC, Chan TY, Hou JY. Effect of berberine on regression of pressure overload induced cardiac hypertrophy in rats. Am J Chin Med. 2002;30:589-599.

66. Huang WM, Yan H, Lin JM, Yu C, Zhang H. Beneficial effects of berberine on hemodynamics during acute ischemic left ventricular failure in dogs. Chin Med J. 1992;105:1014-1019.

67. Zhang W, Chen SG, Ju HS, et al. Mechanisms of protective effects of berberine on ischemia/reperfusion injury in isolated rat heart. Methods Find Exp Clin Pharmacol. 1992;14:677-684.

68. Li BX, Yang BF, Zhou J, Xu CQ, Li YR. Inhibitory effects of berberine on IK1, IK and HERG channels of cardiac myocytes. Acta Pharmacol Sin. 2001;22:125-131.

69. Wang YX, Zheng YM. Ionic mechanism responsible for prolongation of cardiac action-potential duration by berberine. J Cardiovasc Pharmacol. 1997;30:214-222. 
70. Wang YX, Yao XJ, Tan YH. Effects of berberine on delayed after depolarisations in ventricular muscles in vitro and in vivo. J Cardiovasc Pharmacol. 1994;23;716-722.

71. Wang YX, Zheng YM, Zhou XB. Inhibitory effects of berberine on ATP-sensitive $\mathrm{K}^{+}$channels in cardiac myocytes. Eur J Pharmacol. 1996;316:307-315.

72. Huang Z, Chen S, Zhang G, et al. Protective effects of berberine and phentolamine on myocardial reoxygenation damage. Chin Med Sci. 1992;7:221-225.

73. Marin-Neto JA, Maciel BC, Secches AL, Gallo Junior L. Cardiovascular effects of berberine in patints with severe congestive heart failure. Clin Cardiol. 1988;11:253-260.

74. Zeng XH, LI YY. Clinical observations of the effect of berberine for congestive heart failure. US Chin J Angiocardiomyopathy. 2001;6: 308-311.

75. Lau CW, Yao XQ, Chen ZY, Ko WH, Huang Y. Cardiovascular actions of berberine. Cardiovasc Drug Rev. 2001;19:234-244.

76. Huang HL, Chu ZL, Wei SJ, Jiang H, Jiao BH. Effects of berberine on arachidonic acid metabolism in rabbit platelets and endothelial cells. Thromb Res. 2002;106;223-227.

77. Huang CG, Chu ZL, Yang ZM. The progress in pharmacological researches on berberine. Comun Inform Pharm. 1991;9:10-12.

78. Holy EW, Akhmedov A, Lüscher TF, Tanner FC. Berberine a natural lipid-lowering drug, exerts prothrombic effects on vascular cells. J Mol Cell Cardiol. 2009;46(2):234-240.

79. Guo Y, Wang QZ, Li FM, Jiang X, Zuo YF, Wang L. Biochemical pathways in the antiatherosclerotic effect of berberine. Chin Med J. 2008;121:1197-1203.

80. Pandey MK, Sung B, Kunnumakkara AB, Sethi G, Chaturvedi MM, Aggarwal BB. Berberine modifies cysteine 179 of IkappaBalpha kinase, suppresses nuclear factor-kappaB-regulated antiapoptotic gene products, and potentiates apoptosis. Cancer Res. 2008;68:5370-5379.

81. Kim S, Kim Y, Kim JE, Cho KH, Chung JH. Berberine inhibits TPAinduced MMP-9 and IL-6 expression in normal human keratinocytes. Phytomedicine. 2008;15:340-347.

82. Choi BH, Ahn IS, Kim YH, Park JW, Lee SY, Hyun CK, Do MS. Berberine reduces the expression of adipogenic enzymes and inflammatory molecules of 3T3L1 adipocyte. Exp Mol Med. 2006;38:599-605.

83. Chen FL, Yang ZH, Liu Y, et al. Berberine inhibits the expression of TNF-alpha, MCP-1 and IL-6 in AcLDL-stimulated macrophages through PPARgamma pathway. Endocrine. 2008;33(3):331-337.

84. Tan Y, Tang Q, Hu BR, Xiang JZ. Antioxidant properties of berberine on cultured rabbit corpus cavernosum smooth muscle cells injured by hydrogen peroxide. Acta Pharmacol Sin. 2007;28:1914-1918.
85. Hsieh YS, Kuo WH, Lin TW, et al. Perotective effects of berberine against low-density lipoprotein (LDL) oxidation and oxidized-LDL induced cytotoxicity on endothelial cells. J Agric Food Chem. 2007;55:10473-10445.

86. Zhang BJ, Xu D, Guo Y, Ping J, Chen LB, Wang H. Protection by and anti-oxidant mechanisms of berberine against rat liver fibrosis induced by multiple hepatotoxic factors. Clin Exp Pharmacol Physiol. 2008;35:303-309.

87. Hwang JM, Wang CJ, Chou FP, et al. Inhibitory effect of berberine on tert-butyl- hydroperoxide-induced oxidative damage in rat liver. Arch Toxicol. 2002;76:664-670.

88. Sabir M, Bhide NK. Study of some pharmacological actions of berberine. Indian J Physiol Pharmacol. 1971;15:111-132.

89. Kupeli E, Kosar M, Yesilada E, Husnu K, Baser C. A comparative study on the anti-inflammatory, antinociceptive and antipyretic effects of isoquinoline alkaloids from the roots of Turkish berberis species. Life Sci. 2002;72:645-657.

90. Yuan J, Shen XZ, Zhu XS. Effect of berberine on transit time of human small intestine. Zhongguo Zhong Xi Yi Jie He Za Zhi. 1994;14: 718-720.

91. Chan E. Displacement of bilirubin from albumin by berberine. Biol Neonat. 1993;63;201-208.

92. Tan YZ, Wu AC, Tan BY, et al. Study on the interactions of berberine displace other drug from their plasma proteins binding sites. Chin Pharmacol Bull. 2002;18:576-578.

93. Xin HW, Wu XC, Li Q, Yu AR, Zhong MY, Liu YY. The effects of berberine on the pharmacokinetics of cyclosporine A in healthy volunteers. Methods Find Exp Clin Pharmacol. 2006;28:25-29.

94. Wu X, Lu Q, Xin H, Yu A, Zhong M. Effects of berberine on the blood concentration of cyclosporine A in renal transplanted recipients:clinical and pharmacokinetic study. Eur J Clin Pharmacol. 2005;61:567-572.

95. Nies AT, Herrmann E, Brom M, Keppler D. Vectorial transport of the plant alkaloid berberine by double-transfected cells expressing the human organic cation transporter 1 (OCT1, SLC22A1) and the efflux pump MDR1 P-glycoprotein (ABCB1). Naunyn Schmiedebergs Arch Pharmacol. 2008;376(6):449-461.

96. Lin HL, Liu TY, Wu CW, Chi CW. Berberine modulates expression of mdr1 gene product and the responses of the digestive tract cancers to Paclitaxel. Br J Cancer. 1999;81:416-422.

97. Vrzal R, Zdarilova A, Ulrichova J, Blaha L, Giesy JP, Dvorak Z. Activation of the aryl hydrocarbon receptor by berberine in HepG2 and H4IIEcells: Biphasic effect on CYP1A1. Biochem Pharmacol. 2005;70:925-936.
Nutrition and Dietary Supplements

\section{Publish your work in this journal}

Nutrition and Dietary Supplements is an international, peer-reviewed, open access journal focusing on research into nutritional requirements in health and disease, impact on metabolism and the identification and optimal use of dietary strategies and supplements necessary for normal growth and development. The journal welcomes papers covering

\section{Dovepress}

original research, basic science, clinical \& epidemiological studies, reviews and evaluations, guidelines, expert opinion and commentary, case reports and extended reports. The manuscript management system is completely online and includes a very quick and fair peer-review system, which is all easy to use. 